\title{
Reliability and Validity of an Instrument that Measures the Main Challenge Facing the Management and Administration of Water Resources and Services
}

\author{
Tirso Javier Hernández-Gracia ${ }^{1}$, Enrique Martínez Muñoz ${ }^{1}$, \\ Danae Duana Ávila ${ }^{1}$, Cruz García-Lirios ${ }^{2}$ \\ ${ }^{1}$ Universidad Autónoma del Estado de Hidalgo, Pachuca, México \\ ${ }^{2}$ Universidad Autónoma del Estado de México, Huehuetoca, México \\ Email: explorerall@hotmail.com, enriquemarvar@yahoo.com.mx, duananos@yahoo.com.mx, cgarcial213@profesor.uaemex.mx
}

How to cite this paper: Hernández-Gracia, T. J., Muñoz, E. M., Ávila, D. D., \& García-Lirios, C. (2018). Reliability and Validity of an Instrument that Measures the Main Challenge Facing the Management and Administration of Water Resources and Services. Open Journal of Political Science, 8, 353-364.

https://doi.org/10.4236/ojps.2018.84025

Received: May 29, 2018

Accepted: August 26, 2018

Published: August 29, 2018

Copyright $\odot 2018$ by authors and Scientific Research Publishing Inc. This work is licensed under the Creative Commons Attribution International License (CC BY 4.0).

http://creativecommons.org/licenses/by/4.0/

\begin{abstract}
Often, local water issues have been addressed from the perspective of the social actors in relation to their authorities, but the objective of this paper has been to estimate the perception of risk of both rulers who are comfortable and governed in a scenario of shortages, shortages, unhealthy and expensive water service. A non-experimental investigation was carried out with a selection of 248 residents of a locality in northeastern Mexico. The reliability and validity of the WRPS-16 were established, which included two dimensions related to the aversion or delegation of responsibility to the State for the free supply of water and the risk-prone dimension to account for the negotiation and agreement with local managers. However, the type of study, sampling and analysis limited the results to the context of the research, suggesting the inclusion of the hypermetropia factor that explains the lack of concern and the inaction of future generations in the face of risk events and their effects on community health.
\end{abstract}

\section{Keywords}

Natural Disasters, Water Supply, Risk Perception, Pro-Environmental Behaviors

\section{Introduction}

The objective of this work was to establish the reliability and validity of an instrument that measure the perception of risk before municipal water resources and services (García, Sandoval, \& Espinoza, 2018). 
Studies of risk perception in general have shown that risk events such as landslides, floods, droughts, fires, earthquakes or subsidence are the result of absent or deficient civil protection, as well as a propensity to make decisions and actions oriented towards risks (see Table 1).

In the case of water resources and services, risk perception has been associated with risk events with shortages, shortages, unhealthiness and scarcity, highlighting their impact on community health, mainly in vulnerable sectors such as infants whose deaths are around one million per year for the consumption of hydro-transmitted diseases (García, 2018).

However, the studies referred to do not distinguish areas of local development that determine the sustainability of the supply and collection system. This is the case of urban peripheries where water problems are associated with risk events, leading to a scenario of current risks that may be observed in the future in urban centralities and rural areas (García, Carreón, \& Hernández, 2017).

Prospective studies have shown an increasingly lower availability of supply per person in cities that correlates with austere lifestyles and cutting policies, as well as the substantial increase in rates and the proliferation of diseases and not only hydro-transmitted but through vectors such as malaria (García, Rivera, Limón, Bustos, \& Juárez, 2017).

However, the main challenge facing the management and administration of water resources and services is not only the prevention of diseases and the strengthening of a public and community health care system, but also the differentiation between urban and regional centrality, and the semi-rural periphery (Bustos, Juárez, Sandoval, Quintero, \& García, 2017).

Studies of risk perception have centered their interest in the establishment of a co-government system in which civil society is involved in the decision making of preventive health institutions (García, Rivera, \& Limón 2017).

In this sense it is that the trustworthiness and the validity of instruments that allow diagnosing the confidence of the citizenship with its authorities in the matter of supply, quality and rates, not of subsidies and condoning is essential to anticipate scenarios of conflicts and agreements (García, Bustos, Juárez, Ribera, \& Limón, 2017).

However, the instruments that have been used to measure risk perceptions have disconnected the risk events with the consequences on community health and its impact on the decisions and preventive life styles of the inhabitants (Carreón, Juárez, \& García, 2017).

The inclusion of environmental, perceptual, dispositional and administrative determinants on decision-making and preventive risk actions is fundamental to achieve the sustainability of a co-management between political and social actors, as well as between public and private sectors (García, Juárez, \& Sandoval, 2017).

It is a governance system in which civil participation goes beyond an opinion poll or a consultation about its voting intentions in favor of inclusive proposals 
Table 1. State of knowledge.

\begin{tabular}{|c|c|c|}
\hline Year & Author & Find \\
\hline 1987 & $\begin{array}{l}\text { Corral, Garibaldi } \\
\text { \& Encinas }\end{array}$ & $\begin{array}{l}\text { They found in an exploratory study that the use of the shower was the main activity of domestic water consumption. In } \\
\text { contrast, the use of the refrigerant was the domestic device with less frequency of use. }\end{array}$ \\
\hline 1992 & $\begin{array}{l}\text { Corral \& } \\
\text { Obregón }\end{array}$ & $\begin{array}{l}\text { They carried out a systematic review of the variables included in the models of pro-environmental behavior. They } \\
\text { measured the distance between the residence and the recycling depot, the environmental competencies, the styles and } \\
\text { the ecological reasons as the determinants of pro-environmental behavior. }\end{array}$ \\
\hline 2000 & $\begin{array}{l}\text { Corral \& } \\
\text { Zaragoza }\end{array}$ & $\begin{array}{l}\text { They demonstrated through a system of structural equations, four dimensions of recycling behavior, which was } \\
\text { determined by the reasons for reuse. In this model, the size of the house and economic status influenced the behavior. } \\
\text { However, beliefs through motives influenced reuse behavior. The authors established significant differences between } \\
\text { men and women with respect to their knowledge and beliefs about product reuse and recycling. }\end{array}$ \\
\hline 2000 & Hernández et al. & $\begin{array}{l}\text { They made known a difference between proportions of non-parametric data, six categories: image and institutional } \\
\text { identity, physical and built environment, solid waste, hazardous waste, electric power management and environmental } \\
\text { training. Years later, the image of the campus, solid waste and environmental training remained the main problems. }\end{array}$ \\
\hline 2001 & $\begin{array}{l}\text { Acosta \& } \\
\text { Montero }\end{array}$ & $\begin{array}{l}\text { They demonstrated significant associations between responsible environmental behavior, locus of control, knowledge of } \\
\text { environmental action, environmental skills and cognitive coping styles related to denial and acceptance of } \\
\text { environmental deterioration. As the values of one variable increased, the values of the other variable increased. Acosta } \\
\text { and Montero proved that responsible environmental behavior is associated }(\mathrm{r}=0.45 ; p<0.05) \text { with the skills and } \\
\text { knowledge index of environmental action. }\end{array}$ \\
\hline 2001 & Oceja \& Jiménez & $\begin{array}{l}\text { They evaluated a group of standards, analyzed their degree of compliance and established their classification. They } \\
\text { showed that the typology is relevant based on three criteria: personal agreement, formal sanction and social disapproval. } \\
\text { They determined differences between norms (legitimate laws and prescriptions are fulfilled more than illegitimate laws } \\
\text { and convictions) using the criterion of informed and perceived compliance. And they revealed significant differences } \\
\text { between attitudes towards each type of norm. }\end{array}$ \\
\hline
\end{tabular}

2002 Guevara \& They proved the tendency of residents of the City of Puebla to respond positively and homogeneously to garbage Rodríguez separation and collection services.

2002 Negrón, Arias \& They showed significant differences between men and women regarding the change of their knowledge, after Delbrey information relative to their knowledge about their health and the environment.

2003 Corral Revealed through a structural model, the incidence of domestic utensils in water consumption. In this model, the reasons, scarcity and skills, had a negative effect on water consumption.

2003 Frías, López \& They demonstrated the indirect effect of the macrosystem on antisocial behavior through the microsystem. In the Díaz structural model, the exosystem had three indicators and the microsystem with five manifest variables.

2004 Bustos, Flores \& They argued the direct, positive and significant relationship between two behavioral variables pro-environmental: wash Andrade of bathrooms with personal hygiene $(\mathrm{r}=0.17 ; p<0.01)$, toilet of teeth with personal bath $(\mathrm{r}=0.18 ; p<0.01)$.

2004 Corral \& They established six dimensions of sustainable behavior: austerity, anticipation, altruism, effectiveness, deliberation and Pinheiro

2004 Corral, Fraijo \& They revealed four dimensions of water consumption related to the use of basins, showers, irrigation and cleaning. Tapia Later they established, through a structural model, the incidence of ecological and utilitarian beliefs in water consumption. Both beliefs correlated negatively.

2004 Urbina He showed that pollution and scarcity of water are perceived by experts and non-experts as risks.

2005 Aguilar \& Established through a structural model, the indirect effect of attitude, past behavior, control and personal norm on Valencia pro-environmental behavior through intention. In this structure, past behavior was the main determinant of ecological behavior.

They found the moderating effect of environmental knowledge on the causal relationship between affective, verbal and real commitment. To the extent that environmental knowledge was minimal, the causal link and the percentage of variance were low. In contrast, when the level of environmental knowledge was specialized, the causal relationships and the variance explained increased significantly. 


\section{Continued}

2005 Meinhold \& Malkus

2006 Corral, Frías, Fraijo \& Tapia

2006 Corral et al.

2007 Cerda, García, Díaz \& Núñez

2008 Corral et al

2009 Corral, Tapia, Fraijo \& González

2009 Frías, Rodríguez \& Corral

2009 Harranz, Proy and Eguiguren

2009 Orostegui \& Matos

2009 Frías et al.

2009 Gilford

2009 Corral et al

2010 Fernández, Porter \& Neyra

2010 Gissi \& Soto

2010 Hidalgo \& Pisano The perception of risk was determined by attitude $(\beta=0.305, p=0.000)$ and the intention was influenced by self-efficacy $(\beta=0.259, p=0.001)$.

2010 Jiménez \& Lafuente

They correlated self-efficacy with environmental attitudes $(r=0.23)$, with environmental knowledge $(r=0.16)$ and with pro-environmental behavior $(r=0.30)$. Environmental attitudes with environmental knowledge $(r=0.18)$ and with pro-environmental behavior $(\mathrm{r}=0.45)$ and environmental knowledge with pro-environmental behavior $(\mathrm{r}=0.34)$, all with a significance less than 0.001 .

They found significant differences between sex and age with respect to risk propensity; between sex, age and schooling in terms of lack of self-control; between sex and age with respect to antisocial behavior and between sex and age in terms of anti-environmental behavior.

Other relationships with perceptions of time perspective: 1) orientation to the past, 2) future orientation and 3) sustainable styles with dimensions such as: a) this hedonistic, b) present fatalistic, c) positive last d) past negative e) propensity future.

They tested the direct effect of environmental protection on the environmental behavior of the consumer of organic products and the promoter of environmental culture; the causal relationship between the promotion of environmental protection and the environmental behavior of the environmental monitor and the environmental cultural promoter.

They established positive associations between negative past and present hedonist, positive past and present fatalist. The hedonistic present with the positive past and the fatalistic present.

In the context of the psychology of water resources and services, found that the utilitarian beliefs determine water consumption indicated by washing dishes, grooming, watering plants, washes dishes and cleaning sidewalk.

They revealed ten dimensions of sustainable behavior: perception of environmental norms, appreciation for the natural, pro-environmental indignation, affinity for diversity, deliberation, fairness, altruism, pro-ecologism, austerity and self-presentation.

They tested, through a structural model, the effect of the social norm on anti-environmental behavior. In this system of equations, deterrence and the personal norm had a lower incidence or zero in the behavior unfavorable to the environment.

Through a trail model, they established the intention as the main determinant of recycling behavior. In the system of equations, beliefs indirectly influenced recycling and intention was the transmitting variable.

The high stratum (62 kg/inhabitant/day) generated less waste than the medium (74 kg/inhabitant/day) and low (77 $\mathrm{kg} /$ inhabitant/day) strata and with respect to the district average $(71 \mathrm{~kg} /$ inhabitant/day). Organic matter, paper and cardboard were the prevailing municipal waste. In this sense, the high stratum produced recycling waste.

Shows that social norms determine individual principles crystallized into specific actions, but both are embodied in moral standards define an identity based on the context.

Pessimism rather than fatalism is different spatial levels: local, national and global. Consequently, farsightedness is not just a perceptual bias of social, collective and personal standards indicated by their degree of usefulness and hedonism, but also is a bias scenario that the recipient is unknown and homogenized thus to have control or certainty context of water availability.

Modeled both variables with social intolerance and age to show that there was an implicit relationship between environmental conservation and affinity towards nature. In this sense, farsightedness would be linked to social intolerance since the biofilia would immediate and specific conservation actions in the immediate environment, but once guaranteed the existence of species, the individual could develop a hedonism and utilitarianism to its preserved environment.

They found differences between teachers and students regarding their learning environment. While the students considered that their environment had social relevance, the teachers assumed the natural environment as the most important development factor for their community.

For the authors the appropriation of the space is gestated with the tequio, which is the personal work carried out by a member of the collective before entering community work.

He established three factors of the four possible dimensions. The first factor explained $46.4 \%$ of the variance, the second $28.6 \%$ and the third explained $25.15 \%$ of the variance. They determined differences between men and women $\left[\mathrm{X}^{2}=\right.$ $10.088(2 \mathrm{gl}), p=0.007]$, for years $\left[\mathrm{X}^{2}=176.77(8 \mathrm{gl}), p=0.000\right]$ and habitat $\left[\mathrm{X}^{2}=21.657(6 \mathrm{gl}), p=0.001\right]$. 


\section{Continued}

2010 Mariby

In their study, $62 \%$ agreed on a definition of cooperatives, $32 \%$ have a favorable attitude towards collective work, but $35 \%$ disagreed to transform their company into a cooperative.

2010 McCright

According to the author, the political ideology and the perception of understanding negatively determined knowledge about climate change and concern about its consequences in gender $(\beta=-0.372$ and $\beta=0.336$ respectively).

2010 Molini \& Salgado They discovered that around the discussion of the differences between compact and dispersed cities, population density is a relevant factor, since the low concentration in compact cities makes them more sustainable than dispersed cities, but their high density increases costs to the governmental entity responsible for regulating them.

2010 Montilla, Pernía For researchers, corporativism assumes a human and social system indicated by processes of self-construction, \& Rodríguez self-production, self-organization and autopoiesis.

2010 Pasco, Villafuerte They demonstrated that the level of technical-normative knowledge about the National Program on Climate Change \& Neyra was minimal among those in charge of making decisions and training volunteers who will carry out environmental preservation actions.

2010 Schoon, Cheng, They pointed out that attitudes towards social liberalism were determined by education $(\beta=0.25)$, and that these attiGale, Batty \& tudes were integrated by overt variables of anti-racism, social liberalism and gender equality (45, 57 and, 47 respectiveDeary ly).

2010 Sharples

2011 Corral, Mireles, Tapia \& Fraijo

He revealed that the main source of information on climate change was television news (23.9\%); food and beverages are the most consumed by the sample (83.8\%) and the foci were the most used object to combat climate change (88.7\%).

They established by means of a structural model $\left[\chi^{2}=144.36(85 \mathrm{gl}), p<0.001\right.$; NNFI $=0.97$; CFI $=0.97$; RMSEA = $0.03 ; \mathrm{R}^{2}$ proecological behavior $\left.=0.52\right]$ the influence of sustainable behavior on happiness $(0.31)$. The determining factor was reflected in four dimensions: frugality, equity, altruism and proecological behavior $(0.42,0.35,0.66$ and 0.72 respectively).

2011 Flowers \& Vine They realized the significant differences between density, activity, studies, income and use of water with respect to occasional, systematic and absent water savings.

2011 Gaxiola, Frías \& They tested using a structural model $\left[\chi^{2}=14.6(5 \mathrm{gl}), p<0.01\right.$; BBNFI $=0.90$; BBNNFI = 0.86; CFI = 0.96; RMSEA = Figuerero $\left.0.04 ; \mathrm{R}^{2}=0.05\right]$ five reflective factors of protective factors. The latent variable included the factor $k(0.65)$, exosystem (0.27), microsystem (0.79), ontosystem (0.64) and aging (0.22).

2011 Malmod

It systematized the reordering plans based on a logic of exclusion and inclusion. The first consisted in differentiating the spaces; privatization of goods and services. The second set connections between sectors, spaces and services to reduce spatial segregation. The logic of inclusion implies a network design in which each node interconnects with the other and allows the interrelation between the spatial elements, as well as the construction of an urban identity that favors tolerance to diversity.

2011 Marqués et al. They found in a sample of students from a public university a level of knowledge of general and specific environmental problems in reference to their attitudes and behaviors.

2011 McCright \& They showed that beliefs about the null effects of climate change determined confidence in white men with a Dunlap conservative ideology $(\gamma=0.82, p=0.000)$. For its part, the basic political ideology determined the negation of the effects of climate change $(\gamma=0.47, p=0.000)$, the race determined the belief about the lack of consensus on the effects of climate change for white's conservatives $(\gamma=0.38, p=0.000)$. However, sex negatively affected the beliefs of the null effects of climate change of the base respondents $(\gamma=-0.67, p=0.000)$, as well as the influence of identification with environmentalism on the same belief in the same group $(\gamma=-0.81, p=0.000)$.

2011 Nacif \& Espinosa They found a relationship between national identity and the urbanist pragmatism of central spatial rearrangement and architectural designs. The buildings represented symbols of national reconstruction that would extend to other Pampean and South American cities (Brazil, Peru, Colombia and Venezuela).

2011 Nozica He showed that tourism policy encourages the connection between bioceanic and peri-urban corridors. For this purpose, the desirable scenario will consist of a road network that articulates both areas. Such strategy will allow to increase the competitive advantages in terms of tourism, technological and commercial services in the region.

2011 Puntriano

He proved that the bankruptcy of the mill generated a venture in the peasants and employees who decided to administer the company after the conflicts between the actors were resolved with the expropriation in the framework of neoliberalism. 


\section{Continued}

2011 Solis

For the author, the sense of environmental responsibility determined directly, positively and significantly the saving of water for domestic and residential use. The emotional affinity with the environment influenced the residential management of municipal solid waste.

2011 Spence, Portinga, They reported that the prevention of perceived disasters influenced the reduction of energy consumption $(\beta=0.371)$, as Butler \& Pidgeon well as the experience of flooding determined the perceived local vulnerability $(\beta=0.421)$.

2011 Touginha \& Pato They indicated that ecological behavior correlated with age $(r=0.30)$, while ecocentric beliefs were associated with universal values $(r=0.20)$. On the other hand, age and universal values determined the ecological behavior $(\beta=0.24, \beta$ $=0.21, \mathrm{p}=0.001$ respectively).

2011 Zapata \& They found significant differences among residents of nearby areas regarding neuroticism, extraversion and recycling. Castrechin Personality traits were not significantly associated with pro-environmental recycling behavior.

2012 Carr, Patterson,

In their study, people with religious beliefs agreed that they are very connected to the effects of climate change, while skeptics expressed confidence in scientific and technological advances, rather than religious solidarity in the face of the problem of global warming.

2012 Corral, García, They established by means of a structural model $\left[\chi^{2}=540.80(243 \mathrm{gl}), p<0.001\right.$; BBNNFI $=0.93$; CFI $=0.94$; RMSEA $=$ Tapia \& Fraijo $\left.\quad 0.06 ; \mathrm{R}^{2}=0.35\right]$ the indicators of the sustainable behavior factor that included: altruism, proecologism, frugality and equity $(0.74,0.75,0.64$ and 0.74 respectively), while the restoration factor included: well-being, fascination, extension and compatibility $(0.61,0.99,0.94$ and 0.99 respectively).

2012 Cravino

He found a degree of perception of risk in Buenos Aires residents at the time of migrating to the periphery. In this sense, the perception of the habitat is related to the services and investments that the State has oriented towards centrality. Another factor of perception of housing is spatial socialization, since a change of neighborhood implies the loss of social capital. The rent is a phenomenon closely connected with the expectations of appropriation of the space, since a good root guarantees the permanence in the neighborhood and the establishment of a higher quality of life. The proximity between the houses has led to the development of a spatial identity that increases reciprocity and even the transformation of the environment.

2012 Fraijo, Corral, They established the correlations between environmental psychological factors. Austerity correlated with deliberation $(\mathrm{r}=$ Tapia \& García $\quad 0.311, p=0.001)$ and skills $(\mathrm{r}=0.382, p=0.001)$. Deliberation with altruism $(\mathrm{r}=0.415, p=0.001)$, with the propensity to the future $(\mathrm{r}=0.390, p=0.001)$, with beliefs $(\mathrm{r}=0.336, p=0.001)$ and with equity $(\mathrm{r}=0.302) ; p=0.001)$. Altruism with beliefs $(\mathrm{r}$ $=0.279, p=0.001)$. The pro-environmental behavior with the skills $(\mathrm{r}=0.291, p=0.001)$. The propensity to the future with beliefs $(\mathrm{r}=0.323, p=0.001)$ and with the skills $(\mathrm{r}=0.321, p=0.001)$. The reasons with the beliefs $(\mathrm{r}=0.207, p=0.001)$.

2012 Markowitz

He established differences between ethical, unethical and undecided regarding his concern $(\mathrm{F}=102.52, p=0.000)$, risks $(\mathrm{F}=51.68, p=0.000)$, consensus $(\mathrm{F}=26.83, p=0.000)$, efficacy $(\mathrm{F}=34.67, p=0.000)$ and responsibility $(\mathrm{F}=69.41, p=$ $0.000)$. The environmental intentions were determined by beliefs $(\beta=0.506)$.

2012 Moyo et al.

They indicated that the perceived cycle of rain was the phenomenon that most farmers remembered (72\%), while winter was the least remembered event (1\%). The four seasons were remembered as the phenomena of greatest change (23\%), finally, climate change was identified as the main cause of the changes perceived (53\%).

2012 Poortinga, They pointed out that personal norms determined the size of the carbon demand and the supply of alternative technolSpence, Demski $\quad$ ogies $(\beta=0.51$ and $\beta=0.41$ respectively). In turn, beliefs about climate change affected personal norms $(\beta=0.59)$; On \& Pidgeon the other hand, the environmental identity determined the beliefs of climate change $(\beta=0.55)$.

2012 Sahin, Hamide \& They showed that the favorable behavior to the environment was explained by the attitudes toward it $(\beta=0.67)$. In their Teksoz case, the dispositions towards the behaviors in favor of sustainability were determined by the tendency to follow the means of communication $(\beta=0.12)$, although they were also explained by age $(\beta=-0.65)$.

2012 Urquieta \& Campillo

They established a relationship between economic resources and social stratification with respect to the representation of the city. The lower classes perceived centrality as an insecure area. The middle classes were concerned about the expansion of the city and its effects on the environment. As for expectations, they expressed an ideal of a city in which spaces would allow coexistence as an element of inclusion; recovery of space, tranquility and enjoyment. Regarding the right to the city, this was represented as a scenario of freedoms in which access to employment, education and universal health are indispensable.

2012 Yahya, Hashemnia They proved that the attitude correlated with the consumption of green products $\left(\mathrm{R}^{2}=0.457\right)$. The norm was related to \& Rouhi attitudes $\left(R^{2}=0.48\right)$, perceptions with attitudes $\left(R^{2}=0.43\right)$ and consumption with attitudes $\left(R^{2}=0.54\right)$. 


\section{Continued}

2013 Beck, Sinatra \& For the authors, the perception of knowledge correlated with concern $(\mathrm{r}=0.556)$, responsibility $(\mathrm{r}=0.443, p=0.000)$ Lombardi and concern with responsibility $(\mathrm{r}=0.528, p=0.000)$ and responsibility for dissemination $(\mathrm{r}=0.228, p=0.000)$; personal responsibility with teaching $(\mathrm{r}=0.290, p=0.000)$, predictions of students with their knowledge $(\mathrm{r}=0.496, p=$ $0.000)$ and teaching responsibility with feelings of comfort $(\mathrm{r}=0.529 ; p=0.000)$. They established differences between students of science, engineering, business, health, arts and education $\left(\mathrm{v}_{\text {Cramer }}=0.0001\right)$ and responsibility $(\mathrm{v}=0.000)$, feelings of comfort $(\mathrm{v}=0.000)$ and teaching $(\mathrm{v}=0.000)$.

2013 Corral et al.

They found that the virtues were shaped by the factors of humanism, justice and valuation $(0.97,0.98$ and 0.94$)$, while the sustainable behavior included the factors of altruism, proecologism, frugality and equity $(0.63,0.62,0.79$ and 0.74$)$. The virtues of humanity determined the sustainable behavior $(\beta=0.67)$.

2013 Corral, Tapia, Ortiz \& Fraijo

They established by means of a structural model $\left[\chi^{2}=641.82(201 \mathrm{gl}), p<0.0001\right.$; BBNFI $=0.91$; CFI $=0.92$; RMSEA = $0.06]$ two factors of first order, virtues and sustainable behavior, which had a positive correlation (0.67). They included three factors (humanity, justice and moderation) of second order for the case of virtues $(0.97,0.97$ and 0.94 respectively) and four (altruism, proecology, frugality and equity) of second order for the case of sustainable behavior $(0.63,0.69$, 0.79 and 0.74$)$.

2013 Cunsolo et al.

They revealed that climate change is intuitively related to well-being and community identity. In this sense, their interviewees attribute spiritual links with their environment. Well-being is associated with the relationships that the interviewees establish with their environment and the attributions towards the surrounding elements. Health is represented by the identity and attribution that the environment generates.

2013 Dasaklis \& The literature reviewed by the authors attributes a greater relevance to climate change in the productive and Pappis administrative processes. Mainly in the design of processes and operations that reduce the impact of climate change on the environment. It is an environmental responsibility generated from a green agenda but established from the minimization of operating costs.

2013 Cold \& Corral They established by means of a structural model $\left[\chi^{2}=197.15(71 \mathrm{gl}), p<0.001\right.$; $\mathrm{BBNFI}=0.90 ; \mathrm{BBNNFI}=0.91$; CFI $=$ 0.93 ; RMSEA $=0.007 ; \mathrm{R}^{2}=0.67$ ] the individual characteristics of the offenders, which are determinants of antisocial behavior (0.62). The latter were determined by family violence $(0.42)$ and the social environment $(0.41)$. The individual characteristics were: anxiety (0.84), opposite behavior (0.68), ADHD (0.85), depression (0.67), inattention (0.84), low empathy (0.47) and low self-control (0.53). Antisocial behavior included antisocialization (0.76), aggression (0.99) and deviation (0.98).

2013 Tapia, Corral, $\quad$ They established by means of a structural model $\left[\chi^{2}=382.3(243 \mathrm{gl}), p<0.0001 ; \mathrm{NNFI}=0.93 ; \mathrm{RMSEA}=0.003 ; \mathrm{R}^{2}=\right.$ Fraijo \& Durón $\quad 0.57]$ the prediction of happiness based on sustainable behavior $(0.17)$ and this based on behavioral intention (0.76). In turn, the sustainable behavior was determined by proecological behavior $(0.80)$, frugality $(0.66)$, equity $(0.45)$ and altruism (0.41). Finally, the intention was influenced by indignation (0.26) and affinity (0.34).

2013 Vinneta \& Maharaj

2013 Wendling et al. They showed that income determined the preferences for action in the face of climate change $(\beta=0.977, p=0.000)$.

2018 Sandoval, Bustos They reviewed the literature concerning the governance of water sustainability to propose a model in which the \& García perception of risks will be associated with peripheral lifestyles such as the dosage that unlike optimization is intermittent and without some technology that allows it.

2018 García, Juárez y Bustos

They developed a model in which the local management of resources was established based on the uses and customs of rural areas, although command structures were modified, the community assembly continued with tequio and guatza, main activities dedicated to the dosage of water consumption.

2018 Juárez et al.

They established as an indicator of co-management reuse, since both public and civilian actors developed storage and dosage techniques in consumption that allow them to reuse their resources, although each time they are contaminated.

Source: Own elaboration.

in the water supply and collection system (Vázquez, Cruz, Carreón, Hernández, Bustos, \& Sandoval, 2017).

It is necessary to link civil protection strategies with risk-based lifestyles based on water availability and local capacity for collecting, storing, collecting and 
treating wastewater (Bustos, Juárez, Carreón, Quintero, Sandoval, Espinoza, \& García, 2017).

In each category, the perceptions of risk are different if urban centers are compared with recreation and water comfort with respect to urban peripheries with scarcity, lack of sanitation and scarcity (García, Carreón, Hernández, Bustos, \& Aguilar, 2016).

\section{Method}

Are there significant differences between the theoretical dimensions of risk perceptions with respect to the relationships between the factors and indicators observed?

Null hypothesis: There will be significant differences between the theoretical dimensions with respect to the empirical dimensions around the perceptions of risks derived from the local supply and collection system.

Alternative hypothesis: There will be no significant differences between the theoretical dimensions of risk perceptions and the relationships between their factors and indicators to be observed.

A non-experimental, cross-sectional and exploratory study was carried out with a non-probabilistic selection of 248 residents of a municipality in northeastern Mexico, considering the scarcity, shortage, unhealthiness and local scarcity (see Table 2).

The Water Risk Perception Scale (WRPS-16) was built, which includes three dimensions related to aversion to risks and the propensity to risk before capture, storage, optimization and reuse promoted by the municipal government (see Table 3).

Table 2. Descriptive of the sample.

\begin{tabular}{cccccccccccccc}
\hline Sex & $\%$ & Age & $\%$ & Scholarship & $\%$ & Entry & $\%$ & Residence & $\%$ & Consumption & $\%$ & & \\
Woman & 43.1 & $<29$ & 56.2 & $<$ University & 87.2 & $<300$ USD & 34.2 & $<10$ & 21.3 & \\
Man & 67.9 & $>29$ & 44.8 & $>$ University & 13.8 & $>300$ USD & 66.8 & $>10$ & 79.7 & $>200$ & 43.8 \\
\hline
\end{tabular}

Source: Prepared with the study data.

Table 3. Construction of the (WRPS-16).

\begin{tabular}{|c|c|c|c|c|}
\hline Factor & Concept & Indicator & Measurement & Interpretation \\
\hline $\begin{array}{l}\text { Aversion to } \\
\text { risk }\end{array}$ & $\begin{array}{l}\text { It refers to the collaboration between political and } \\
\text { social actors in relation to the governance of water } \\
\text { resources and services (García, Carreón, Bustos, \& } \\
\text { Juárez, 2016). }\end{array}$ & $\begin{array}{l}\text { I will negotiate the } \\
\text { establishment of rates } \\
\text { after the local or federal } \\
\text { elections }\end{array}$ & $\begin{array}{l}0=\text { "not likely" up } \\
\text { to } 5=\text { "quite } \\
\text { likely" }\end{array}$ & $\begin{array}{l}\text { A high score reflects a } \\
\text { governance of water resources } \\
\text { and services indicated by } \\
\text { perceptions of risk control }\end{array}$ \\
\hline $\begin{array}{l}\text { Propensity } \\
\text { to risk }\end{array}$ & $\begin{array}{l}\text { Refers to the delegation of responsibility to the State } \\
\text { or civil society based on the universal right of access } \\
\text { to water, the gratuity of the service, the prevention of } \\
\text { water-borne diseases and the subsidy for development } \\
\text { (García, Carreón, \& Hernández, 2016) }\end{array}$ & $\begin{array}{l}\text { The State must provide an } \\
\text { indispensable minimum } \\
\text { of water to residences free } \\
\text { of charge }\end{array}$ & $\begin{array}{l}0=\text { "not likely" up } \\
\text { to } 5=\text { "quite } \\
\text { likely" }\end{array}$ & $\begin{array}{l}\text { a high score reflects a } \\
\text { codependence rather than a } \\
\text { congestion of water resources } \\
\text { and services }\end{array}$ \\
\hline
\end{tabular}

Source: Prepared with the study data. 
Participants were surveyed in their place of residence and/or work, with a written guarantee of confidentiality and anonymity, as well as a warning that the results of the study would not affect their status.

The information was processed in IBM-SPSS-AMOS version 25.0. The multivariate Crombach's alpha and the parameters of adequacy, sphericity, validity, fit and residual for the contrast of the null hypothesis were estimated.

\section{Results}

Table 4 shows the internal consistency values of the general scale and the subscales which exceeded the minimum required of 0.700 (general alpha of 0.789 , alpha of the aversion of 0.780 and alpha of the propensity of 0.785 ).

Once the constructs that explained $39 \%$ of the total variance were established, we proceeded to contrast the null hypothesis relative to the significant differences between the theoretical dimensions of risk perception with respect to the factors and indicators found.

The adjustment and residual parameters $\int \mathrm{X}^{2}=567.32(45 \mathrm{gl}) p=0.009 ; \mathrm{CFI}=$ 0.990 ; GFI $=0.995$; RMSEA $=0.009$ j suggest the non-rejection of the null hypothesis, although the total variance suggests the inclusion of another factor that

Table 4. Descriptive of the instrument.

\begin{tabular}{cccccccc}
\hline R & M & SD & SW & K & A & F1 & F2 \\
\hline R1 & 4.35 & 1.01 & 1.58 & 1.58 & 0.782 & & 0.456 \\
R2 & 4.30 & 1.03 & 1.40 & 1.48 & 0.793 & & 0.426 \\
R3 & 4.13 & 1.04 & 1.37 & 1.85 & 0.785 & & 0.491 \\
R4 & 4.26 & 1.08 & 1.65 & 1.94 & 0.790 & & 0.485 \\
R5 & 4.83 & 1.09 & 1.92 & 1.68 & 0.781 & & 0.483 \\
R6 & 4.18 & 1.01 & 1.58 & 1.83 & 0.793 & & 0.481 \\
R7 & 4.27 & 1.02 & 1.38 & 1.59 & 0.762 & & 0.401 \\
R8 & 4.01 & 1.03 & 1.25 & 1.92 & 0.761 & 0.481 & \\
R9 & 4.85 & 1.04 & 1.36 & 1.94 & 0.794 & 0.406 & \\
R10 & 4.82 & 1.01 & 1.47 & 1.86 & 0.726 & 0.483 & \\
R11 & 4.39 & 1.07 & 1.54 & 1.79 & 0.740 & 0.491 & \\
R12 & 4.16 & 1.08 & 1.58 & 1.83 & 0.751 & 0.481 & \\
R13 & 4.27 & 1.01 & 1.32 & 1.57 & 0.782 & 0.456 & \\
R14 & 4.02 & 1.01 & 1.45 & 1.69 & 0.714 & 0.436 & \\
R15 & 4.18 & 1.03 & 1.36 & 1.50 & 0.746 & 0.481 & \\
R16 & 4.11 & 1.04 & 1.59 & 1.67 & 0.782 & 0.401 & \\
\hline Re1 & & & & & \\
R & & & & & \\
\end{tabular}

$\mathrm{R}=$ Reactive, $\mathrm{M}=$ Media, $\mathrm{SD}=$ Standar Desviation, $\mathrm{SW}=$ Swedness, $\mathrm{K}=$ Kurtosis, $\mathrm{A}$ = Alpha de Crombach's. Adecuation $(\mathrm{KMO}=0.783)$, Sphericity $\left(\mathrm{X}^{2}=346.32(34 \mathrm{gl}) p=0.000\right)$. Extraction: Main Axes, Rotation: Promax. F1 = Aversion to risks ( $24 \%$ of the total variance explained), F2 = Propensity to Risks ( $15 \%$ of the total variance explained). All items are answered with any of five options ranging from $0=$ "not likely" to 5 = "quite likely". Source: Prepared with the study data 
the literature identifies as hyperopia to demonstrate a tenure towards carelessness and inaction in the face of risk events and water problems both global and local.

\section{Discussion}

The contribution of this work to the state of the question lies in the establishment of the reliability and validity of an instrument that measured the perception of risks, but the type of non-experimental study, the type of non-probabilistic sampling and the type of exploratory analysis they limited the results to the research scenario, suggesting the inclusion of the hyperopia factor to account for the lack of concern and inaction in the face of risk events and their effects on public health.

García, Juárez, \& Bustos (2018) showed that local water governance depends on the conciliation of uses and customs rather than on the implementation of water supply and comfort strategies that suppose consumption of more than 200 liters per person.

In the present work it has been highlighted that the uses and customs only generate aversion to the risks in the best of cases, but the clientelist relationship between the violated sectors with their authorities rather develop perceptions of risk associated with the propensity or Delegation of responsibility to the government, prelude to the lack of concern and inaction before the events of risk and their effects on public health.

Juárez, Bustos, Quintero, García, \& Espinoza (2018) showed that in the area of cooperation co-management can be indicative of co-government, although the increase in propensity to risk suggests that in the best of cases, solidarity will be observed inside of native peoples.

In the present study, the cooperation would be related to an aversion to the risks when the actors are willing to carry out the solidary efforts to carry out the tequio or guatza, main uses and local customs of dosage of water consumption.

Sandoval, Bustos, \& García (2018) proposed a model for the study of local governance, although they started from the assumption that self-management and technology would be sufficient for the establishment of co-management.

In the present work, co-management replaces civil self-management and state self-management since the propensity to risk implies the exclusion of actors from being civil for politicians or vice versa.

It is necessary to include hypermetropia for the study of governance and local water sustainability if differences prevail between urban centrality and periphery.

\section{Conclusion}

The objective of this paper has been to establish the reliability and validity of an instrument that measured two dimensions of the perception and risks related to the aversion or delegation of the problem to the political or social actor, as well 
as the dimension of the propensity involved in negotiation. and agreement between the parties, but the type of study, sampling and analysis limited the results to the research scenario, suggesting the inclusion of the hyperopia factor to explain the effect of the risk events on the mental health of the locality that would be characterized by a lack of concern and inaction before the problems of shortages, unhealthiness and lack of water service.

\section{Conflicts of Interest}

The authors declare no conflicts of interest regarding the publication of this paper.

\section{References}

Bustos, J. M., Juárez, M., Carreón, J., Quintero, M. L., Sandoval, F. R., \& García, C. (2017). Press Coverage around the Problem Water in the Political Election. International Journal of Environment, Agriculture \& Biotechnology, 3, 1-20.

Bustos, J. M., Juárez, M., Sandoval, F. R., Quintero, M. L., \& García, C. (2017). Quality and Fares of Water Supply Services Perceptions for Users in Mexico City. Journal Education \& Social Development, 11, 20-31.

Carreón. J., Juárez, M., \& García, C. (2017). Governance of Water Sustainability. Administrative Science, 1, 241-255.

Corral, V., Bonnes, M., Tapia, C., Fraijo, B., Fríace, M., \& Carrus, G. (2009). Correlates of Pro-Sustainable Orientation the Affinity towards Diversity. Journal of Environmental Psychology, 29, 34-43. https://doi.org/10.1016/j.jenvp.2008.09.001

Corral, V., Fraijo, B., \& Tapia, C. (2008). An Observational Record of Individual Consumption of Water; Applications for Research or $\mathrm{n}$ of Sustainable Behavior. Revista Mexicana de Analysis of Behavior, 34, 79-96.

Corral, V., Fraijo, B., \& Pinheiro, J. (2006). Sustainable Behavior and Time Perspective: Present, Past, and Future Orientation and Their Relationships with Water Conservation Behavior. American Journal of Psychology, 40, 139-147.

Frías, M., Rodríguez, A., \& Corral, V. (2009). A to Analysis of Factors Influencing the Development of Environmental Standards and the Anti-Ecol Behavior or Logic. Interamerican Journal of Psychology, 43, 309-322.

García, C. (2018). Interpretation of Speeches around the Subsidy of the Water Supply Services for the Understanding of Narratives Tariff. Social Sciences, 4, 25-40.

García, C., Bustos, J. M., Juárez, M., Rivera, B. L., \& Limón, G. A. (2017). Expectations of Users of the Potable Water Services around Supply, Quality and Tariffs in the Context of Future Elections in a Locally Mexico City. Compendium, 4, 33-54.

García, C., Carreón, J., \& Hernández, J. (2016). Public Security Governance Based of Ideas of Identity and Risk Perception that Have Been Established by the Media within the Citizens Agenda. Social Work, 11, 103-116.

García, C., Carreón, J., \& Hernández, J. (2017). Cogestion as Security Device for Sustainable Local Development. Eureka, 14, 268-289.

García, C., Carreón, J., Hernández, J., Bustos, J. M., \& Aguilar, J. A. (2016). Specification a Sociopolitical Hyperopia Model. Blue Moon, 42, 270-292.

García, C., Carreón. J., Bustos, J. M., \& Juárez, M. (2016). Scenarios Regarding the Stablishement of an Agenda for Transgenerational Governance of Water Resources and 
Services. Civilizar, 16, 86-112.

García, C., Juárez, M., \& Bustos, J. M. (2018). Specification for a Model of the Study of Local Governance. Sincronía, 22, 459-472.

García, C., Juárez, M., \& Sandoval, F. R. (2017). Model of Water Disposal. Science Political, 32, 1-26.

García, C., Rivera, B. L., \& Limón, G. A. (2017). Perception Model of Sustainability in the Millennial Generation. Inclusions, 4, 82-96.

García, C., Rivera, B. L., Limón, G. A., Bustos, J. M., \& Juárez, M. (2017). Specification of a Consensus Sustainability Model. International Journal of Social Science \& Research, 13, 201-224.

García, C., Sandoval, F. R., \& Espinoza, F. (2018). Sociopolitical Axes for the Governance of the Quality of Social Services. Documental Science, 4, 38-46.

Gilford, R. (2009). Temporal and Spatial Optimism Pessimism in Environmental Assessment. Journal of Environmental Psychology, 29, 1-12. https://doi.org/10.1016/j.jenvp.2008.06.001

Juárez, M., Bustos, J. M., Quintero, M. L., García, C., \& Espinoza, F. (2018). Governance of Water Sustainability Specification for a Model of the Study of Cooperative Reuse. Invurnus, 13, 33-43.

Sandoval, F. R., Bustos, J. M., \& García, C. (2018). Exploratory Testing of a Local Water Sustainability Governance Model. Gestión de la Personas y Tecnología, 31, 72-87.

Vázquez, F., Cruz, M. G., Carreón, J., Hernández, J., Bustos, J. M., \& Sandoval, F. R. (2017). Agenda of the Governance of Water Services in Demarcation of Mexico City. Global Advances Research Journal of Agricultural Science, 6, 1-17. 